\title{
EFFECT OF USING WHEY POWDER ON THE PROPERTIES OF PULP AND PAPER OBTAINED FROM STORED BAGASSE
}

\author{
PEJMAN REZAYATI-CHARANI, AHMAD AZIZI MOSSELLO and MOHAMMAD BERVAIE \\ Department of Cellulose Technology Engineering, Natural Resources Faculty, Behbahan Khatam Alanbia \\ University of Technology, Behbahan, Iran \\ × Corresponding author: P. Rezayati-Charani, rezayati@bkatu.ac.ir
}

Received December 25, 2020

The aim of this study was to investigate the effect of using whey powder (different concentrations and treatment repetitions) as a probiotic agent on the quantitative and qualitative properties of stored bagasse intended for use in the pulp and paper industry. For this purpose, whey powder was added in three concentrations and the treatment was applied once or twice. After that, soda pulp was prepared under conventional conditions. Then, handsheets $\left(80 \mathrm{~g} / \mathrm{m}^{2}\right)$ were made and tested in terms of paper properties, and the results were compared. The findings revealed that increasing the concentration of whey powder and the number of treatments significantly improved the pulp and paper characteristics, thus, using the treatment with $2 \%$ whey powder twice and $0.4 \%$ whey powder once led to the best results for bagasse protection in terms of quality of the raw material, pulp and handsheets.

Keywords: probiotics, whey powder, bagasse, soda pulp, chemical contents, pulp and paper properties

\section{INTRODUCTION}

For centuries, forests have been the main source of paper fibers, but over-exploitation of forests to meet the growing needs of humans has severely reduced their ability to regrow. As a consequence, in most parts of the world, this natural resource has become unavailable for the paper industry and paper mills are facing a shortage of raw materials. For this reason, the use of agricultural wastes and non-wood resources, such as sugarcane, wheat straw, hemp, etc., has been considered for pulp and paper production, and there is a constantly growing body of research dedicated to this type of resources.

Among non-wood resources, the fibrous sugarcane residue, which is called bagasse, has a special position, with its distinctive features such as easy availability, abundance and low collection costs, and a wider range of applications in papermaking, particleboard manufacture, alcohol production etc. However, because of its sugar content, this residue of sugar factories can be attacked by harmful microorganisms, which reduces its quality. ${ }^{1}$ Sugarcane bagasse has 2 to $4 \%$ residual sugar content, which makes it prone to the attack of bacteria and fungi during storage. Thus, proper storage of bagasse is very important, as the storage of raw materials has a fundamental role in maintaining their quality, as well as the quality of the final product, also ensuring the continuation of the production throughout the year. ${ }^{2}$ Because of the seasonal nature of the sugarcane crop (harvested from November to February), bagasse consuming industrial units are forced to store large volumes to continue production during the rest of the year. Therefore, research on appropriate and environmentally friendly storage methods is essential to maintain the quality properties of bagasse.

Various methods, such as dry storage (25-25\% humidity) and wet storage (50\% humidity or 85$90 \%$ humidity), have been developed and used for storing bagasse in the cellulose industry. ${ }^{3}$ Wet storage is done by a biological treatment known as the Ritter method, which is performed by mixing a biological liquid enriched with sugarcane molasses or sugar cane and sprinkling it on the stored bagasse. This method was first performed by Ernest Ritter in 1964 at the 
Ledesma plant in Argentina and was welcomed in other factories due to its significant improvement in the results of bagasse storage. ${ }^{4}$ Other substances used for this purpose include the enzyme protexin, which has also led to positive results in maintaining the quality of bagasse during storage. ${ }^{5}$ In this regard, whey powder can be mentioned as another inexpensive material that contains bacteria producing acidic compounds as a probiotic.

Whey powder is one of the by-products of dairy factories - a white to light creamy substance, with a mild taste, that is obtained from enzyme by the enzymatic method and dried. Recently, the use of protein-containing substances, such as whey powder, has received much attention. Whey powder with protein and salt can be used due to its good nutritional properties in other products, such as meat products, soups, confectionery and chocolate, preventing waste of resources and environmental pollution. Whey powder can also act as a probiotic due to its organic matter, minerals, proteins and $\mathrm{B}$ vitamins and a variety of acids, including lactic acid. ${ }^{5,6}$ Probiotics are sometimes used to control the invasion of harmful microorganisms. In this study, the effect of using whey powder as a probiotic for bagasse storage will be evaluated.

\section{EXPERIMENTAL}

\section{Materials}

Fresh bagasse fibers were prepared at Pars Paper Factory, located in Hafttapeh, Khuzestan, and transferred to the factory's Pulp and Paper Laboratory. Whey powder was prepared at Pegah Lorestan Khorramabad Pasteurized Milk Company in Khuzestan. Also, starch glue was received from Pars Khoshepardaz Company, 96\% alcohol from Khorramshahr Alcohol Manufacturing Company, and other necessary materials for determining the kappa number and for chemical analysis were purchased from Merck, Germany.

\section{Methods}

Samples of fresh and depithed bagasse remained in the laboratory for one week to achieve equilibrium moisture with the environment. Then, $1000 \mathrm{~g}$ of bagasse (based on dry weight - dried in a vacuum oven at $103{ }^{\circ} \mathrm{C}$ for $24 \mathrm{~h}$ ) was selected for each sample. Whey powder, with concentrations of 1,2 and $4 \%$ based on OD weight of bagasse, was dissolved in 1 liter of water and sprayed once or twice (at a 90-day interval), using a sprinkler (Fig. 1). The humidity of all bagasse samples was adjusted to about $50 \%$, and the samples were placed in a closed 20-liter plastic barrel in the laboratory at a temperature of 30 to $40{ }^{\circ} \mathrm{C}$ under the same conditions. The $\mathrm{pH}$ of fresh bagasse, treated and control samples were measured using an MI150 $\mathrm{pH}$ meter.

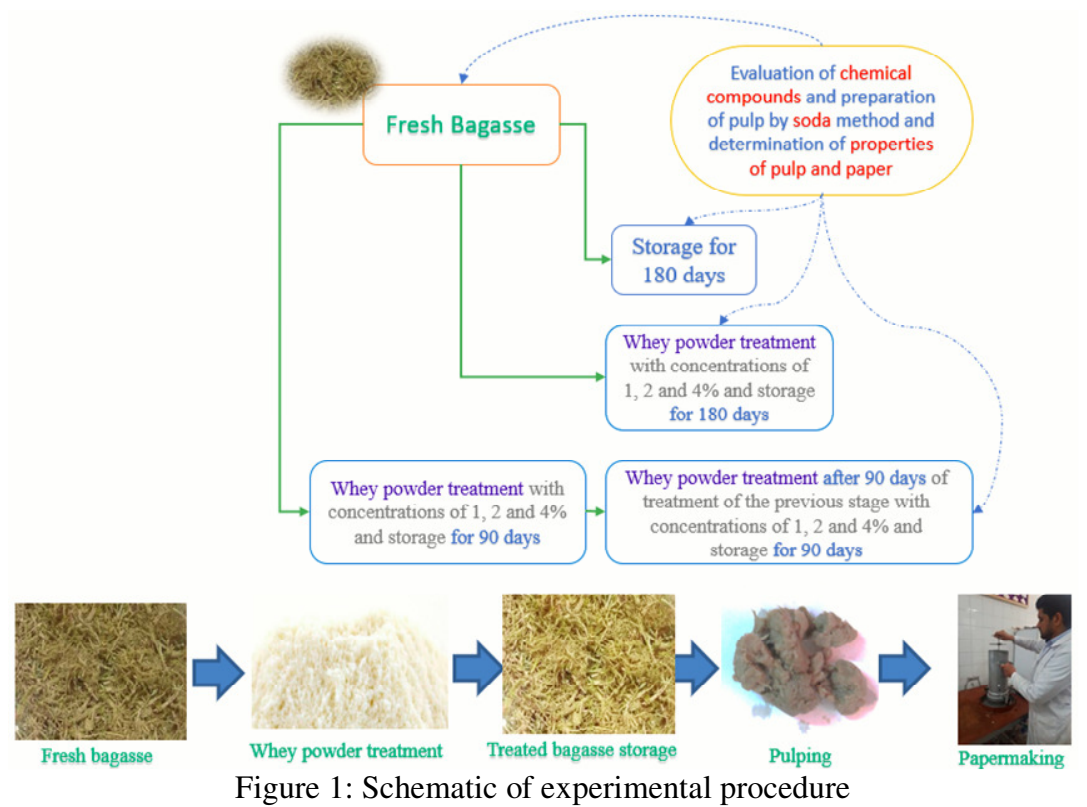

Samples of fresh bagasse, and untreated and whey powder-treated stored bagasse were turned, separately, to powder according to TAPPI standard method $\mathrm{T} 257 \mathrm{~cm}-85$. To determine the percentage of extracted materials, Soxhlet extraction was performed using acetone solvent by the standard method number $\mathrm{T}$ $204 \mathrm{~cm}-97$. The content of lignin was determined by the standard method number 222 ohm-02, 
holocellulose - by the sodium chloride $\operatorname{method}^{7}$ and cellulose - by the Kirschner-Hafner method using nitric acid. ${ }^{8}$

Bagasse samples were cooked using a Haato-tuote oy laboratory cooking digester, located in the research laboratory of Pars Paper Factory, by the soda method, under usual cooking conditions for bagasse applied at Pars Paper Factory (active alkalinity 17\%, cooking temperature $170{ }^{\circ} \mathrm{C}$, cooking time 30 minutes, ratio of cooking liquid to raw material 10:1). Then, the cooked fibers were refined in a refiner (Qomis Processing Company), with a distance of $3 \mathrm{~mm}$ between the discs, and then washed, while the shives were separated using a plate disc with a 20 mesh. The resulting pulp was air dried after dewatering for 48 hours. After weighing, it was collected and stored in sealed bags. Pulp consistency was determined by drying the samples in a vacuum oven at $103 \pm 2{ }^{\circ} \mathrm{C}$ for 24 hours and the yield - by the gravimetric method. Handsheet papers, with a weight of $80 \mathrm{~g} / \mathrm{m}^{2}$, were made according to the TAPPI standard method number T $205 \mathrm{sp}-02$, using a hand-made paper machine.

The characteristics of pulps and papers were measured according to TAPPI standard methods, namely, the kappa number of pulp (T 236 om-99), drainage time (T 221-om-93), thickness (T411 om-05), tear index (T414 om-04), burst index (T403-om-91) and light scattering coefficient (T425 om-01). All statistical calculations were performed based on a completely randomized design with SPSS software, using a comparison of means with one-way analysis of variance and Duncan grouping.

\section{RESULTS AND DISCUSSION pH of bagasse mass}

Figure 2 (a) shows the evolution of $\mathrm{pH}$ in fresh and stored bagasse over a period of 180 days. According to these results, fresh or green bagasse has a $\mathrm{pH}$ of 8.2 , while storage significantly reduces the $\mathrm{pH}$ of bagasse. This is considered to be caused by the lack of lignin and the presence of residual sugar in bagasse. The first is related to the early harvest of bagasse to achieve higher sugar content, while the second - to the incomplete extraction of sugar during sugarcane processing, which is known to lead to the formation of nutrients for yeasts. ${ }^{5}$ Due to the activity of yeasts, the sugars in bagasse are converted to ethyl alcohol, which, when combined with water or moisture in bagasse, is converted to acetic acid, which lowers the $\mathrm{pH}$ of the bagasse mass. On the other hand, if bagasse is treated with whey powder, due to the presence of bacteria in the whey powder that produce acidic compounds, it reduces the $\mathrm{pH}$ of the bagasse by producing lactic acid and creates an anaerobic environment, which inhibits the activity of harmful microorganisms. ${ }^{9}$

\section{Weight loss of bagasse during storage}

Figure 2 (b) shows the weight loss percentage of stored bagasse over 180 days. The storage of bagasse without treatment has caused a $20.70 \%$ drop in bagasse weight. Increasing the number of treatment steps (one and two treatments) and the concentration of whey powder (1,2 and $4 \%$ based on dry weight) has significantly reduced the weight loss of bagasse. As can be seen, treating the bagasse twice, using whey powder with concentrations of 4 and $2 \%$, resulted in the lowest decrease $(10.11 \%)$ in the weight of stored bagasse, i.e. a twice lower weight loss (20.7\% vs. $10.11 \%)$.

The results of analysis of variance confirmed that both factors (concentration and number of treatment steps), as well as their interaction, have a significant effect on weight loss during bagasse storage, which is also consistent with the results of previous studies. ${ }^{5}$ As mentioned previously, destructive microorganisms active under aerobic conditions are the main cause of the reduction of bagasse mass during storage, ${ }^{1}$ and various factors, such as temperature, $\mathrm{pH}$ and the amount of available oxygen, affect their activity. ${ }^{10}$ It seems that the addition of whey powder to bagasse leads to the preservation of its mass, by creating an acidic environment and anaerobic conditions, and thus, reducing the activity of destructive and undesirable microorganisms. ${ }^{11}$

\section{Extractive materials}

Green bagasse had the highest percentage (3.33\%) of extractives (Fig. 2 (c)). Upon storage, the extractives content was reduced, which could be caused by the activity of common microorganisms present during storage of bagasse, which reduces the content of sugars and extractive materials. ${ }^{5}$ Based on these results, the whey powder treatment during storage significantly reduced the amount of extractives. Based on the analysis of variance of the extracted material results, the concentration of whey powder and the number of treatment steps have a significant effect on reducing the percentage of extractive material remaining in the bagasse at the end of storage. For this reason, the storage of bagasse, and especially with the addition of whey powder treatment, can be considered as an advantage due to the reduction in the content of extractives. 

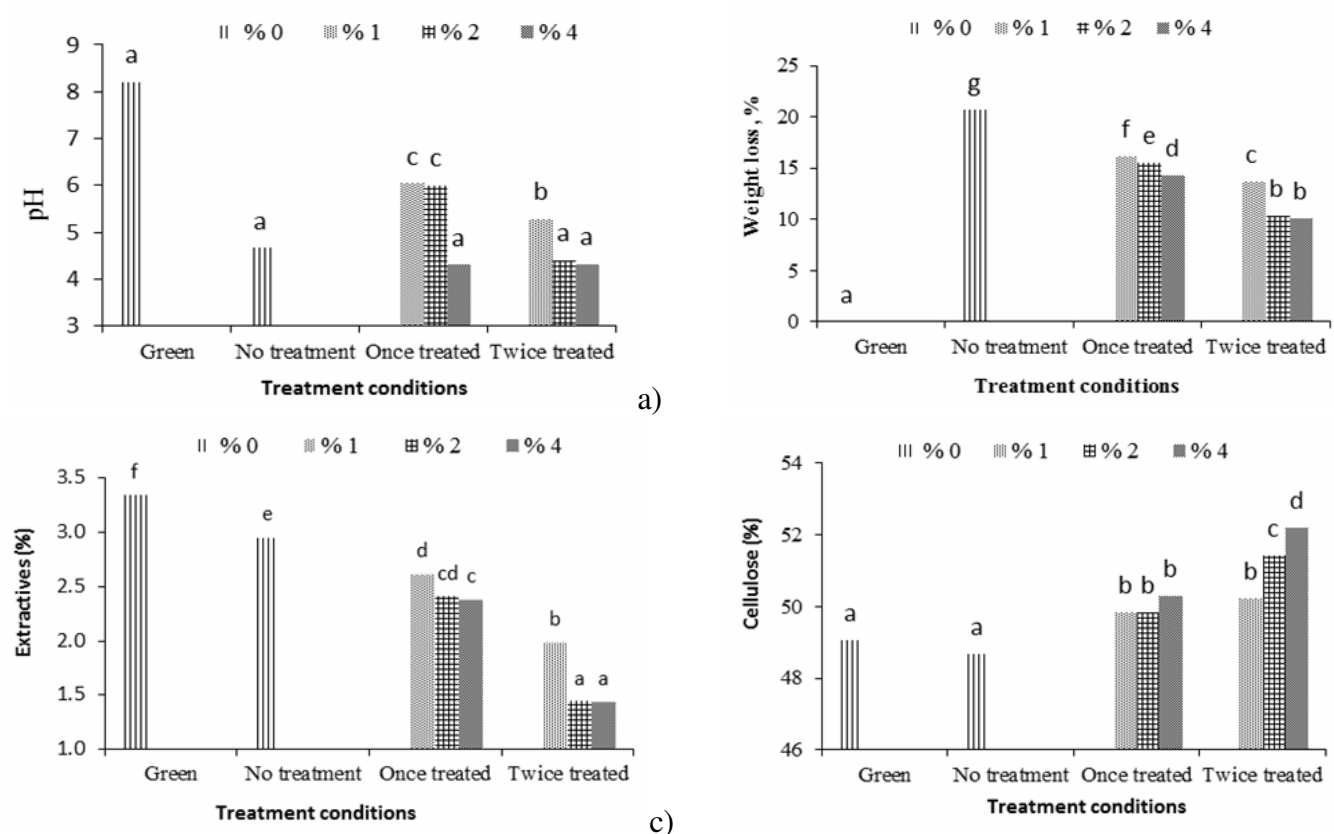

a)

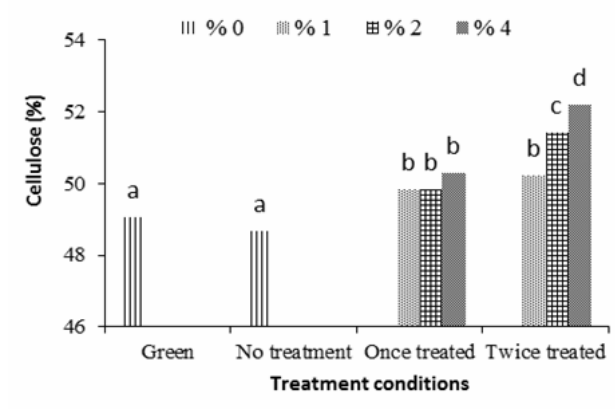

b)

and number of treatment steps on $\mathrm{pH}$ (a), weight loss

Figure 2: Effect of whey powder concentration and number of treatment steps on pH
percentage (b), extractives (c) and cellulose content (d) of bagasse

\section{Cellulose}

The amount of cellulose in untreated bagasse relatively decreased after six months of storage (Fig. 2 (d)). This trend is consistent with the results reported by Khalilian et al. ${ }^{12}$ Decreased cellulose content because of the activity of destructive microorganisms has also been reported by other researchers. ${ }^{1}$ However, the treatment with whey powder in higher concentrations and its reapplication led to preserving the cellulose content during storage. It seems that an increasing total cellulose percentage and a decreasing percentage of extractives in the bagasse treated with whey powder, compared to green bagasse, can indicate that the amount of cellulose actually remains constant due to the protective role of whey powder. ${ }^{5}$ Higher cellulose content means a higher pulp yield and better paper strength properties, which is an advantage in papermaking. ${ }^{13}$

\section{Hemicelluloses}

Hemicelluloses are another major ingredient in bagasse, which due to its hydrophilic nature, during the cooking process and pulp refining, improves sheet formation by water absorption and swelling. ${ }^{14}$ The percentage of hemicelluloses in fresh bagasse decreased during the six-month storage, similarly to cellulose. The use of whey powder reduces the loss of hemicelluloses during storage (Fig. 3 (a)), which is consistent with the results reported by Azizi Mossello et al. The analysis of variance applied to the hemicellulose results revealed that the concentration of whey powder and the number of treatments had a significant positive effect on bagasse hemicelluloses. Therefore, it can be concluded that the use of whey powder to treat bagasse during storage can be considered beneficial for papermaking.

\section{Lignin}

The content of lignin in fresh bagasse was $20.44 \%$; it is observed to have increased to $23.27 \%$ during bagasse storage for 180 days, which, on the one hand, can be due to the resistance of lignin to the attack of microorganisms, ${ }^{15}$ and on the other hand, can be explained by the decrease in the contents of cellulose, hemicelluloses and extractives, caused by bagasse fermentation. The use of whey powder, by helping to preserve cellulose and hemicelluloses against the attack of microorganisms during bagasse storage, while reducing the extractives, has led to a reduction in the content of lignin at the end of the storage period, compared to stored untreated bagasse (Fig. 3 (b)). The analysis of variance for the lignin 
content indicates a significant effect of both factors (concentration of whey powder and number of treatments). Lower lignin content facilitates the cooking process and increases cooking efficiency, reducing the environmental impact of the process. ${ }^{13}$ Therefore, the treatment with whey powder is recommended for storage of bagasse intended for use in the pulp and paper industries, as it reduces the lignin content.

\section{Total pulp yield (unscreened pulp)}

The total yield of fresh bagasse soda pulp was $63.19 \%$ on the initial dry weight basis. After bagasse storage without treatment, pulp was produced with a lower yield (61.26\%) (Fig. 3 (c)), which, as mentioned previously, was caused by fiber degradation. Physically and chemically, during storage bagasse is under the attack of destructive microorganisms. ${ }^{16}$ The use of different concentrations of whey powder $(1,2$ and $4 \%)$ and numbers of treatments (one and two) not just prevented a decrease in total pulp yield, but even increased it, as also confirmed statistically. The results of the analysis of variance for total pulp yield indicated a significant effect these factors, at a 95\% confidence level. The increase in pulp yield is explained by the maximum protection provided by whey powder as a probiotic to the bagasse against fiber degradation during storage, by creating an anaerobic environment, which reduces the growth and development of undesirable microorganisms. ${ }^{11,17}$

\section{Pulp rejects}

According to Figure 3 (d), the fresh bagasse pulp shows a rejects fraction of $14.12 \%$ by weight. After storing the bagasse for six months, the screening rejects increased to $18.75 \%$. This increase may be due to better resistance and stability of lignin against microorganisms and an increase in the share of lignin in untreated bagasse. $^{15,18}$ These conditions lead to incomplete cooking of bagasse and an increase in pulp rejects. ${ }^{19}$ However, the use of whey powder, with different concentrations (1,2 and 4\%) applied in one or two treatment steps, has reduced the pulp rejects fraction.

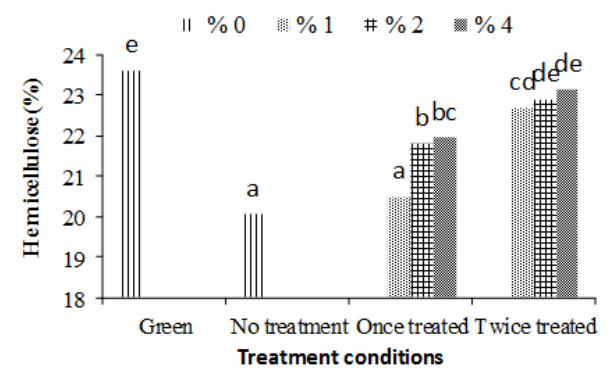

a)
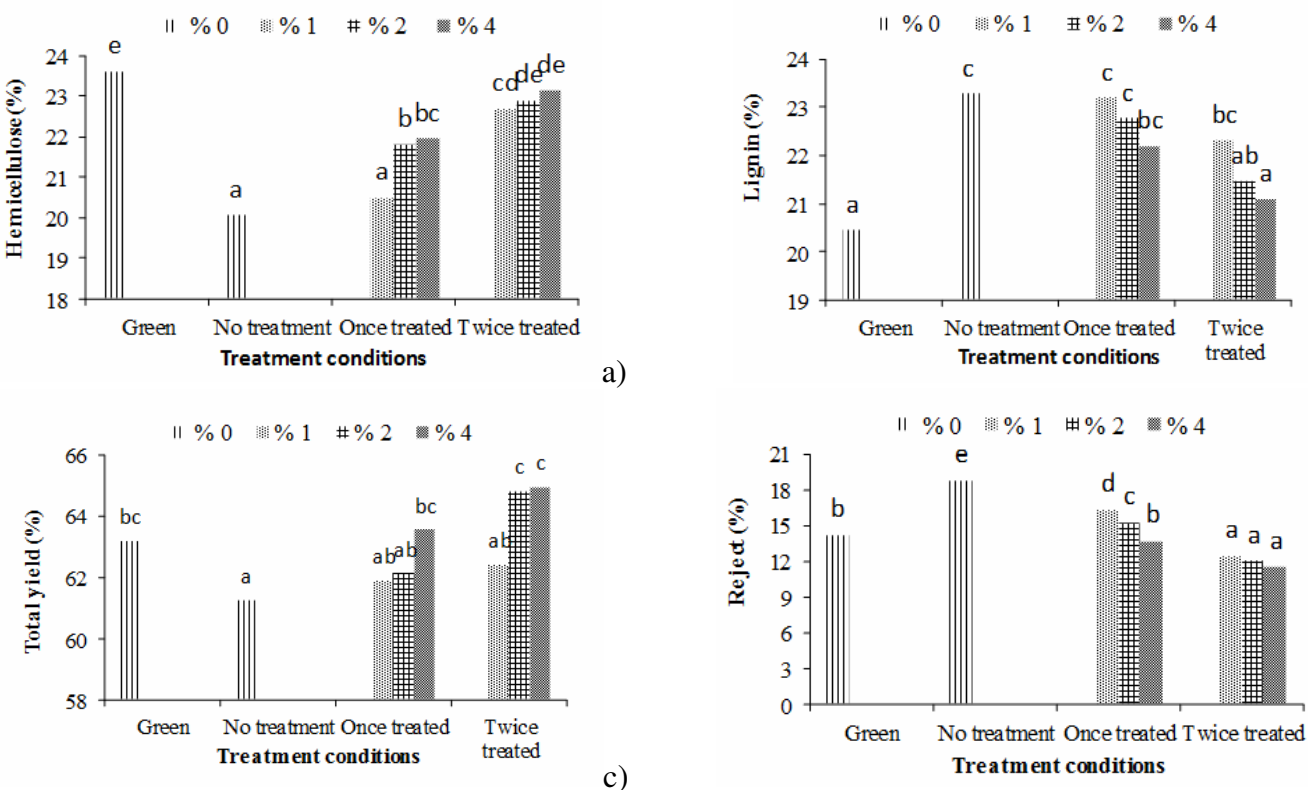

b)

Figure 3: Effect of whey powder concentration and number of treatment steps on the content of

hemicelluloses (a) and lignin (b) in the bagasse mass, as well as on the total pulp yield (c) and pulp rejects (d) of the resulting soda brown pulp

The results of analysis of variance for pulp rejects also showed that both of these factors (concentration and number of treatments) had a significant effect, at the $95 \%$ confidence level, on the pulp rejects. It appears that, by helping to preserve cellulose and hemicelluloses and reducing the percentage of extractives and lignin during storage, the 
treatment of bagasse with whey powder makes cooking easier, more efficient and leads to a higher pulp yield. ${ }^{5,13}$

\section{Kappa number}

According to the obtained results, the kappa number of fresh bagasse pulp was 26.39 (Fig. 4 (a), which can increase to 38.63 , if the bagasse is stored without treatment. The use of different concentrations of whey powder (1,2 and 4\%) applied once or twice reduced the kappa number of the obtained pulps. The analysis of variance for kappa number confirms the significant effect of both these factors, namely, the percentage of whey powder and the number of treatments, as well as their interaction, on the resulting kappa number of the pulp. In addition, the findings of this study are consistent with those of our previous research. ${ }^{5}$ As observed above, the storage of bagasse without treatment has led to an increase in pulp rejects and thus, to an increase in kappa number. On the other hand, the treatment with whey powder as a probiotic had a protective role during the storage of bagasse (preserving the physical and chemical composition of fibers), thus facilitating the cooking and reducing the kappa number.

\section{Pulp drainage time}

Figure 4 (b) exhibits the drainage time of soda pulps obtained from fresh and stored, treated and untreated bagasse. As may be noticed, the drainage time of the fresh bagasse pulp was 16.51 seconds, and it reduced to 11.24 seconds after storage of bagasse without treatment for six months. However, the drainage time of the pulps reduced even more, when the bagasse was treated with different concentrations of whey powder in one or two treatment steps. The analysis of variance for pulp drainage time confirmed that these factors, the concentrations of whey powder and the number of treatment steps, had a significant effect on pulp drainage time (at a $95 \%$ confidence level).

Short pulp drainage time is favorable in papermaking, in terms of the production speed of the paper machine. Reducing drainage time is considered a critical factor in paper machine runnability. The results obtained for drainage time may be explained by the fact that during the storage of bagasse for six months, the consumption of sugars facilitated the separation of pith and fines from bagasse, thus decreasing the contact surface and contributing to easier water drainage from the pulp..$^{19,20}$

\section{Light scattering coefficient of paper}

According to the results of Figure 4 (c), the light scattering coefficient of $80 \mathrm{~g}$ paper made from fresh bagasse soda pulp was about 35.16 $\mathrm{m}^{2} / \mathrm{kg}$, which, in the case of handsheets prepared from recently made pulp from untreated bagasse stored for 180 days, reached $39.72 \mathrm{~m}^{2} / \mathrm{kg}$. In contrast, the light scattering coefficient of $80 \mathrm{~g}$ paper made from bagasse treated with whey powder decreased, compared to that of untreated bagasse. The analysis of variance for the light scattering coefficient of handsheets indicated that the concentration of whey powder and the number of treatment steps were significant factors at a 95\% confidence level. As mentioned above, during the storage of untreated bagasse, under the destructive effects of harmful microorganisms, the contents of cellulose and hemicelluloses are reduced and consequently, the content of lignin increases. ${ }^{15,18}$ In this case, the raw material can be expected to produce a pulp with less formability and more porosity at the time of sheet formation, resulting in a higher light scattering coefficient of the paper. ${ }^{5,19,21}$ On the other hand, the whey powder treatment protects the bagasse against the physical and chemical degradation of fibers during storage, preserving the cellulose and hemicelluloses and reducing the proportion of extractive materials, which results in better handsheet formability and paper with less porosity and lower light scattering coefficient. The light scattering coefficient is an indicator of the bonding among the fibers. The lower the light scattering coefficient, the less empty space and thus, tighter bonding among the fibers. ${ }^{22,23}$

\section{Density of paper}

As shown in Figure 4 (d), the density of $80 \mathrm{~g}$ papers made from fresh bagasse pulp was about $0.324 \mathrm{~g} / \mathrm{m}^{3}$, while, in the case of paper prepared from recently made pulp from untreated bagasse stored for 180 days, it decreased to $0.278 \mathrm{~g} / \mathrm{m}^{3}$. It should be noted that, due to storage of bagasse without treatment, one can expect weaker fiber flexibility and thus, higher porosity and consequently lower density of handsheets. ${ }^{5,21}$ In contrast, the use of whey powder treatment, in different percentages and especially with its repeated application, has increased the density of papers, which has been also proven by the 
statistical analysis. This trend is consistent with the results of previous research., ${ }^{5,22,23}$ The reasons for these changes are the same as previously mentioned for the thickness and other properties of the pulp and paper. In general, whey powder

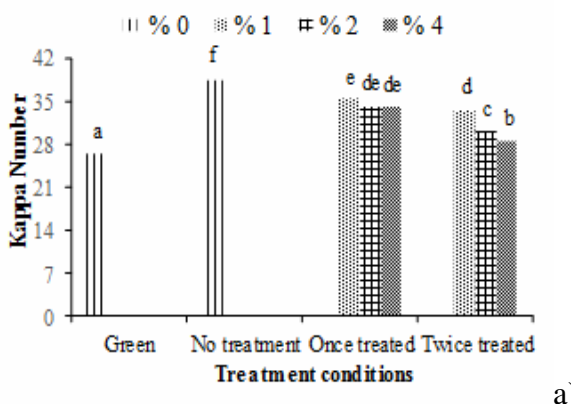

a)

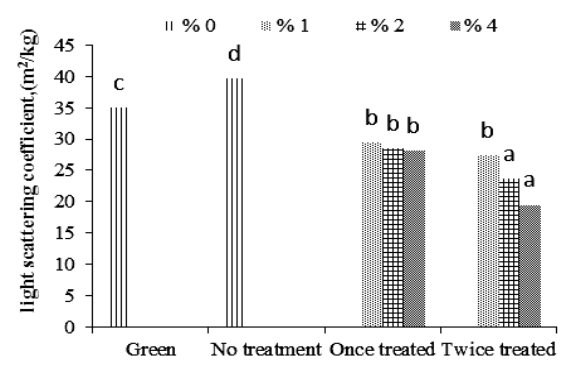

Treatment conditions treatment controls the growth of microorganisms and facilitates the cooking process, leading to better handsheet formation, reducing the thickness and increasing the density of the resulting paper.

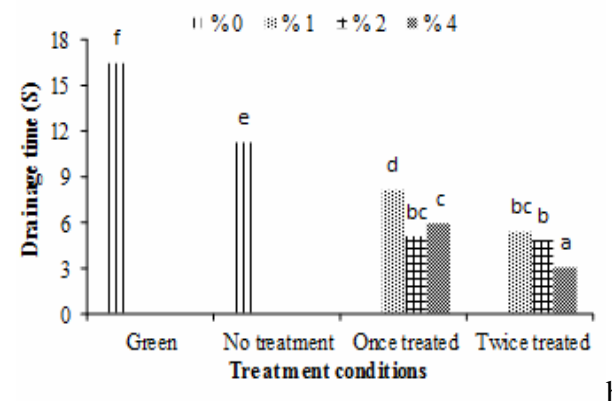

b)

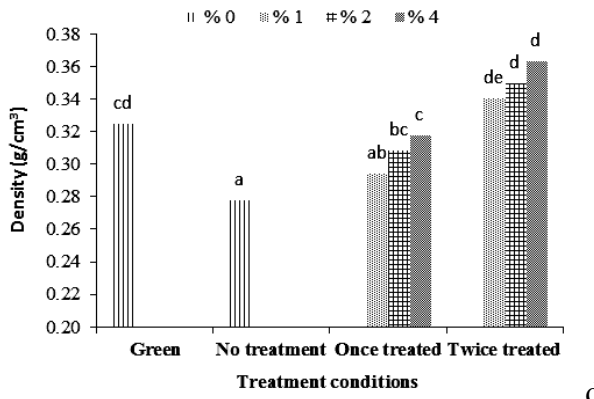

d)

Figure 4: Effect of whey powder concentration and number of treatment steps on kappa number (a), drainage time (b), light scattering coefficient (c) and density (d) of the resulting paper

\section{Tear index}

According to the results displayed in Figure 5 (a), the tear index of handsheets made from fresh bagasse soda pulp was about $5.26 \mathrm{mNm} / \mathrm{g}$, while it reached $4.73 \mathrm{mNm} / \mathrm{g}$ for handsheets prepared from pulp made from untreated bagasse stored for 180 days. The data in Figure 5 (a) also indicate that, after the bagasse was treated with whey powder, the tear index of the manufactured papers improved significantly. The analysis of variance confirmed the significant effects of the concentration of whey powder and the number of treatment steps on the tear index of handsheets. The findings of this study are consistent with those reported by Azizi Mossello et al. ${ }^{5}$ Considering that tear resistance primarily depends on the length and strength of fibers, and secondarily on the bonding among them, ${ }^{22}$ it seems that the whey powder treatment allowed producing quality pulp, and ultimately, handsheets with high tear resistance.

\section{Burst index}

As shown in Figure 5 (b), the burst index of 80 $\mathrm{g}$ papers made from fresh bagasse pulp was about
$2.49 \mathrm{kPa} / \mathrm{g}$, but it decreased to $1.96 \mathrm{kPa} / \mathrm{g}$ for the paper corresponding to untreated bagasse stored for 180 days. However, the treatment of bagasse with different concentrations of whey powder and its repetition improved the burst index of the fabricated paper, which is consistent with the results of Azizi Mossello et al., who treated the bagasse with an enzyme called protexin to protect it during storage. Statistical analysis of the results for burst index indicated the significant effect of the concentration of whey powder and the number of treatments applied on the burst index of paper on the $95 \%$ confidence level.

The burst index is affected by two important factors: fiber length and fiber bonding. ${ }^{24}$ During storage of bagasse without treatment, the growth of harmful microorganisms causes serious damage to the fibers, which in turn leads to incomplete cooking of bagasse and thus reduces the quality of pulp. Decreased pulp quality, in turn, weakens the possibility of bonding between the fibers and ultimately leads to paper with poor properties. Using whey powder as a probiotic during storage of bagasse has proven to have a positive effect on the quality of pulp (reducing the 
kappa number and increasing the total yield), protecting the fibers (based on the results for cellulose and hemicelluloses contents) and facilitating the cooking process (based on the results for pulp rejects). This has led to good strength properties of manufactured papers (enhancing tear index and burst index).

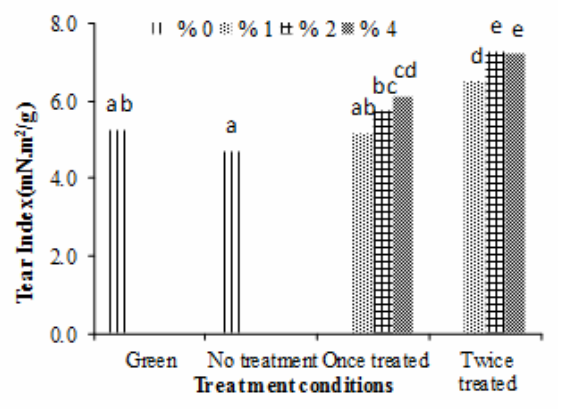

a)

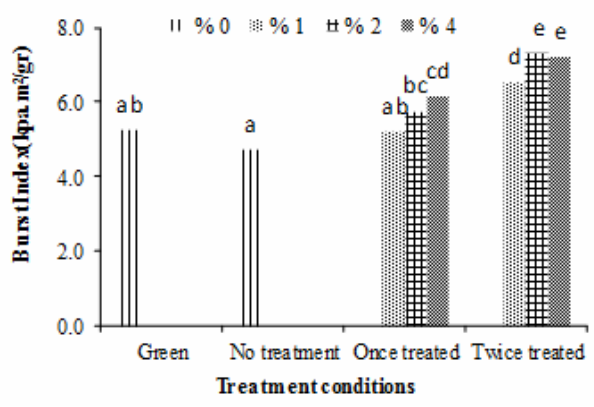

b)

Figure 5: Effect of whey powder concentration and number of treatment steps on tear index (a) and burst index (b) of paper produced from bagasse brown soda pulp

Analysis of the pulp and paper properties obtained in this study for fresh and stored bagasse, untreated and treated with whey powder during storage, has revealed that the whey powder treatment of bagasse allows producing a betterquality pulp (higher total yield, less pulp rejects and lower kappa number) by protecting the fibers against the attack of harmful microorganisms. The higher the concentration of whey powder and the frequency of the treatment, the more significant is the improvement in the quality of the pulp. Also, during the storage of bagasse, due to the consumption of sugars along with the fibers, easier separation of pith and fines occurs, which can provide better conditions for the cooking process, leading to the production of pulp with lower kappa number and higher freeness and facilitating pulp drainage, which finally, increases the paper machine runnability.

As regards the properties of paper, it seems that storage of bagasse without treatment produces fibers with less formability, the paper becomes thicker, has a higher scattering coefficient, lower density and weaker strength properties. On the other hand, the use of whey powder treatment, due to its protective role during the storage of bagasse, allows producing papers with lower thickness and scattering coefficient, and with higher density and resistance properties. As the concentration of whey powder and the frequency of the treatment rise, the quality of the produced paper is significantly enhanced. It can be concluded that the higher the concentration of whey powder and the number of applications, the greater the improvement observed in the quality of bagasse. The treatment with $4 \%$ whey powder provided the best protection for the bagasse, ensuring suitable raw material quality, and good pulp and paper properties.

\section{CONCLUSION}

During storage, bagasse suffers a sharp decline in quantity and quality, which has a negative effect on the cooking process and on the quality of final products. Thus, proper storage of bagasse is strictly needed. According to the findings of this study, the treatment of bagasse with whey powder during the storage period can prevent its damage by microorganisms and reduce some sources of sugars and extractives, as a result, facilitating the cooking process. Altogether, it can be concluded that higher concentrations of whey powder and the repetition of the treatment led to more significant improvement in the quality of bagasse, as well as of the produced pulp and paper.

ACKNOWLEDGEMENT: Financial support for this research was provided by the Behbahan Khatam Alanbia University of Technology, which is appreciated. Also, the authors wish to thank the Pars Paper Industries for providing bagasse and the facilities for its storage.

\section{REFERENCES}

1 J. Lois-Correa, A. Flores-Vela, D. Ortega-Grimaldo and J. Berman-Delgado, J. Appl. Res. Technol., 8, 365 (2010), icat.16656423.2010.8.03.460 
2 M. Habibi, L. A. Jahan and S. Mahdavi, Iran. J. Wood Paper Res. Sci., 32, 541 (2017), https://doi.org/10.22092/IJWPR.2017.110679.1416

3 A. Adam, A. H. Basta and H. El-Saied, Forest

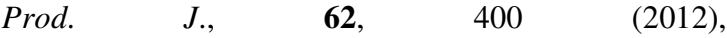
https://doi.org/10.13073/0015-7473-62.5.400

4 P. J. Manohar Rao, IPPTA, 23, 11 (1986), https://ippta.co/wp-content/uploads/2021/01/IPPTA234-11-19-Modern-Bagasse-Handling.pdf

A. Azizi Mossello, A. Savari and P. RezayatiCharani, Iran. J. Wood Paper Ind., 10, 457 (2019), http://www.ijwp.ir/article_35860_en.html

${ }^{6}$ E. Jankowska, A. Duber, J. Chwialkowska, M. Stodolny and P. Oleskowicz-Popiel, Chem. Eng. J., 345 , 395

(2018),

https://doi.org/10.1016/j.cej.2018.03.180

L. E. Wise, M. Murphy and A. A. D'Addieco, Paper Trade J., 122, 35 (1946)

8 G. L. Franklin, Nature, 155, 51 (1945), https://doi.org/10.1038/155051a0

9 S. So, A. Cherdthong and M. Wanapat, J. Anim. Sci. Technol., $\quad$ 62, $648 \quad$ (2020), https://doi.org/10.5187/jast.2020.62.5.648

10 N. Peng, Z. Yao, Z. Wang, J. Huang, M. T. Khan et al., Biotechnol. Biofuels, 14, 152 (2021), https://doi.org/10.1186/s13068-021-02004-x

11 M. J. Salabar and F. Maza, "Non-Wood Plant Fiber Pulping: Progress Report $\mathrm{N}^{\circ}$ 2”, Tappi Press, Atlanta, Georgia, 1970

12 M. Khalilian Shalamzari, M. A. Sadatnia and H. R. Pirayesh, Iran. J. Wood Paper Res. Sci., 32, 509 (2018), https://doi.org/10.22092/IJWPR.2017.109270.1386

13 A. Rodríguez, A. Moral, L. Serrano, J. Labidi and L. J. B. T. Jiménez, Bioresour. Technol., 99, 2881 (2008), https://doi.org/10.1016/j.biortech.2007.06.003

14 C. J. Biermann, "Handbook of Pulping and Papermaking”, $2^{\text {nd }}$ ed., Academic Press, 1996, pp. 139, https://www.elsevier.com/books/handbook-of-pulpingand-papermaking/biermann/978-0-12-097362-0

15 M. Kim, G. Aita and D. F. Day, Appl. Biochem. Biotechnol., $\quad$ 161, 34 (2010), https://doi.org/10.1007/s12010-009-8827-1

16 V. Ramaswamy, T. Ramanathan and T. Venkataraman, in Procs. Pulping Conference, 1989, https://agris.fao.org/agrissearch/search.do?recordID=US9150385

17 H. J. I. B. Sharma, Int. Biodeterior., 23, 329 (1987), https://doi.org/10.1016/0265-3036(87)90022-4

18 M. Joonobi, S. Salehpour, Z. Araznia and Y. Hamzeh, Iran. J. Wood Paper Res. Sci., 31, 58 (2016), https://doi.org/10.10.22092/IJWPR.2015.105610

19 A. A. Mossello, J. Harun, H. Resalati, R. Ibrahim, S. R. F. Shams et al., BioResources, 5, 2112 (2010), https://ojs.cnr.ncsu.edu/index.php/BioRes/article/view/ BioRes_05_4_2112_AziziMossello_HRIFM_Kenaf_f or_Paper_Board/702

${ }^{20}$ J. Villar, E. Revilla, N. Gómez, J. Carbajo and J. L. Simón, Ind. Crop. Prod., 29, 301 (2009), https://doi.org/10.1016/j.indcrop.2008.06.002

21 R. S. Seth, Solutions!, 1, 95 (2001), available at: http://pascal-

francis.inist.fr/vibad/index.php?action=getRecordDetai $1 \& i d t=13745364$

22 D. Page and J. M. MacLeod, Tappi J., 75, 172 (1992), https://www.bcin.ca/bcin/detail.app?id=115312

23 D. C. Mohta, D. N. Roy and W. Phill, Tappi J., 3, 9 (2004), available at: http://pascalfrancis.inist.fr/vibad/index.php?action=getRecordDetai $1 \&$ idt $=15693880$

24 C. E. Brandon, in "Pulp and Paper: Chemistry and Chemical Technology", vol. 3, $3^{\text {rd }}$ ed., edited by $\mathrm{M}$. Ek, G. Gellerstedt and G. Henriksson, Berlin, 2009 